\title{
Would Adorno Download Music? Piracy, the Recording Industry and Reproduction Reconsidered
}

\author{
David Arditi
}

My first interaction with Ben Agger came after he invited me to give a presentation to the Center for Theory. The Center was established as a place to advance intellectual camaraderie at the University of Texas at Arlington and beyond. For me, this presented an opportunity for me to meet more scholars at UTA in the humanities and social sciences. I decided that my paper would be called "On Piracy," a theoretical engagement with Adorno about reproduction in the digital era. "Downloading is Killing Music: The Recording Industry's Piracy Panic Narrative" was recently accepted in $\underline{\text { Civilisations, }}$ and this presentation would be an attempt to turn from a Cultural Studies textual analysis to a deeper critical theoretical engagement with the idea of piracy. Agger was not a fan of the title "On Piracy," and encouraged me to consider "Would Adorno download music? piracy, the recording industry and reproduction reconsidered." After I agreed to the title change, Agger's emailed response was "Of course, Adorno wouldn't even have sent email, let alone 'tweeted'! Benjamin might have, though!" The paper evolved into an engagement with Adorno largely on the idea of reproduction. What follows is the paper from that presentation.

The transition from analog music to digital music gave us the perfect opportunity to rethink what it means to perform, record, and distribute music. Interestingly, these three aspects of music (performance, recording and distribution) are all parts of musical reproduction. At different moments in history, reproduction has had significantly different meanings as musical reproduction has shifted to adjust to the social relations of production. Most recently, the recording industry has been trying to deal with the implications of digital reproduction. Specifically, major record labels, in collaboration with the Recording Industry Association of America (RIAA), attempt to redefine musical reproduction as the execution of any digital music file. In the late 1990s, they began to argue that every time a music file is played on a computer, it creates a "copy" in random-access-memory (RAM). While this redefinition of reproduction has not been widely accepted, this at least has been the position of the recording industry and it was nearly codified in law. During the Clinton Administration, Patent Commissioner Bruce Lehman introduced a government white paper that would attempt to make the RIAA's position the law. After several years of debate, when the concepts from this white paper finally passed as the Digital Millennium Copyright Act (DMCA), it did not retain this definition of reproduction that considered each RAM execution a copy. Had this definition of reproduction been made the law, it would have redefined musical reproduction and ownership in the digital era as every play of a song would have required authorization. As Agger contends about the acceleration of fast capitalism, "nothing today is off limits to the culture industries and other industries that colonize not only our waking hours but also our dreaming" (Agger 2004a:3). By expanding reproduction to the execution of files, the recording industry would further colonize and commodity our consumption of culture.

The main issue here has to do with copyright law, the ideological apparatus that supports the commodification of culture. If playing a digital music file creates an unauthorized reproduction of music, then people playing music on their computers is potentially a violation of copyright law, even if the person playing the music purchased it legally. However, when discussions about piracy boiled over into the news media, it was not about consumers playing music on their computers, but rather, file-sharers downloading and uploading music from peer-2-peer networks. 
For more than a decade, the journalists have been obsessed with piracy in relation to any discussion about digitization of the culture industries. Whether discussing film, television, newspapers or music, journalists engage a piracy panic narrative about how digital files signal the downfall of traditional media commodities. My research addresses this narrative in relation to the music industry (Arditi 2014a, 2014b). The piracy panic narrative of the recording industry argues that file sharing is piracy, piracy is stealing, and stealing hurts artists and their labels. Therefore, the major record labels argue that music fans who file share are not listening to free music, but rather, they are stealing income from their favorite artists. Finally, the RIAA claims that this will lead to the end of recorded music as we know it. For William Patry, head copyright lawyer for Google and one of the most prolific scholars of copyright law, this narrative is "the result of calculated political strategies to psychologically demonize opponents to make them appear to be 'bad' people" (Patry 2009:44). By labeling file-sharers as deviant criminals, the recording industry creates a platform from which to get legislators to act.

However, from the start, there is one massive hole in their argument: file-sharing is not piracy. Patry describes the way that metaphors are used to turn file-sharing from an innocent activity to one of the most reprehensible acts of the high seas.

With regard to copyright policy, piracy is the unauthorized commercial reproduction of copyrighted material. By claiming that file sharing is piracy, the industry has made the argument that copyright infringement occurs in the refusal to pay, not just in the unauthorized sale. This is to say nothing about the legality of file-sharing under copyright law, but only to point to the term piracy. In this definition of piracy, there is an explicit connection between piracy and capitalism. If people attempt to reproduce copyrighted material for profit without authorization, they are violating capitalist order. By establishing copyright law, the state provides the apparatus through which capital can exploit musicians and profit from the sale of culture.

It is easy enough to stop here: file sharing is not piracy because it is not commercial in nature. But I want to point to a deeper parallel between file-sharing and its connection to capitalism. I think that if we look closely at the term "reproduction" in this context it points to an inherent connection between musical reproduction and capitalism. For instance, what does it mean to reproduce music? How is reproduction connected to capitalism?

Interestingly, Theodor Adorno was working on a manuscript that was released posthumously entitled Towards a Theory of Musical Reproduction. Of course, Adorno's object of study is far removed from digital files, since he passed away in 1969 - long before mp3s and the Internet were a consideration for musical reproduction. However, this work does help to contribute to a critique of the concept of musical reproduction. Before I get to his theory of reproduction, I would like to begin by working through the concept in terms of its contemporary usage and work back towards Adorno's theory.

\section{Theorizing Musical Reproduction}

Today, I think that most people would uncritically accept that a definition of "musical reproduction" would involve making copies of recorded music. A rather encyclopedic definition of musical reproduction states that it "had its origins in the late nineteenth century . . . with an history of gradual improvements in fidelity, realism and portability" (Shuker 2012:315). Here the origin of musical reproduction connects with the invention of the gramophone and contains a technological determinism about the constant improvement of music reproduction technologies. This definition requires musical reproduction to be connected to a technology that can produce sound. The definition is technological determinist because it removes the inventors of sound reproduction machines from the discussion. Roy Shuker's definition imagines these machines that magically show up through the logic of progress which will always increase sound fidelity, become more realistic, and increase in portability. Jonathan Sterne provides a much more realistic version of the development of sound reproduction that focuses on the people who invented audio playback and recording technology (Sterne 2003). Significantly, Shuker's definition points to the fact that everyone who owns a music player (be it a tape deck, CD player, phonograph, or computer) can initiate the performance of music with this technology - musicians do not have to be around to reproduce music.

However, we cannot forget that musical reproduction goes back further than the gramophone. The first mass reproduction of music was made available by the printing press. According to Paul Théberge:

Although musical notation and sound recording are, in most respects, fundamentally different from one another - both 
technically and with regards to their modes of production, distribution, and consumption - there are, nevertheless, ways in which notation has prepared the social, cultural, and economic ground for sound reproduction. Both notation and sound recording were initially conceived of as primarily mnemonic or reproductive technologies, but each has, in its own manner, become productive; that is, each has become a vehicle for the planning and creation of musical works (Théberge 2006:289).

Théberge's concept of musical reproduction places notation as vital to the reproduction of sound. Rather than sound by a machine, musical notation enables reproduction by performance. Furthermore, Théberge claims that notation enabled large scale production of music in the form of symphonies and orchestras. Without notation, it would be difficult for a large group of musicians to coordinate a large complex musical composition. But more importantly, musical notation creates the capacity for musicians that never communicate with each other to play the same composition. The printing press enabled the mass reproduction of music by creating copies of a work that can be distributed globally.

Copyright law acknowledges these different types of musical reproduction by creating parallel copyrights. These include performance, publishing, mechanical and print copyrights. The copyright contains "the exclusive right to reproduce, publish, and sell copies of the copyrighted work, to make other versions of the work, and, with certain limitations, to make recordings of and perform the work in public" (Krasilovsky et al. 2007:89). Copyright owners can do all of this with their rights, and licenses allow copyright owners to give others the authority to exercise these rights. In other words, one person can own a copyright, but still license another person to reproduce that music. I want to highlight here that reproduction, performance, and composition become three different spheres in this legalistic understanding of reproduction. One person could own the copyright to perform, reproduce and print a song, but this does not have to be the case; and more importantly, the segmentation of copyrights into these discreet spheres disfigures the idea of reproduction itself. Above all, reproduction and printing are the same process - to record sound is to write sound. This point about discreet spheres and their relationship to reproduction will be important when I discuss Adorno later.

For scholars of popular music, there is no distinction between production and reproduction of music. Simon Frith contends that "Twentieth-century popular music means the twentieth-century popular record; not the record of something ... which exists independently of the music industry, but a form of communication which determines what songs, singers and performances are and can be" (Frith 2006:232). Here popular music is understood, above all, as a recording. When rock bands make music, they go into the studio and record it - they do not write each individual part and come together to perform the recording as Bach or Beethoven would have with an orchestra. Though Frith does overstate this position by negating the individual writing process. Popular music happens in the studio and is a product of the technology available in the studio at the time of recording. There is no pop music without the intermediation of a recording. The fact that music is being recorded shapes the way that music is produced.

Where Frith celebrates the role of recording in the studio, Adorno laments the impact that technology has on the creation of music. Rather than heralding in the new capacities of the recording studio, Adorno criticizes the way that technology shapes music production. For instance, Adorno explains that "the only thing that can characterize gramophone music is the inevitable brevity dictated by the size of the shellac plate" (Adorno 2002b:278). If the physical medium can hold only five minutes worth of music, songs produced in that format will be limited to five minutes in length. If a medium can hold 60 minutes of music, then record labels will develop a way to fill that format with as much music as possible. Because audiences became accustomed to songs that were the length of a "side," songs have generally continued to adhere to those length limitations. At different moments, the recording industry has adopted different forms of recordings that integrate with different media formats. For instance, concept albums are longer compositions unified around a similar theme where each song on an album becomes a movement. These longer thematic albums were the result of there being more space available on an LP to record more music. In turn, the concept album is based on the idea of creating one overall artistic work in the form of multiple "sides." There is a direct relationship between the medium and the commodity; as changes occur in the music commodity's medium, the form (i.e. single or album) of the commodity is changed by the recording industry to better market the music commodity. With Adorno's critique of technology in the recording studio in mind, I will now turn to his theory of musical reproduction.

\section{Adorno's Theory of Musical Reproduction}

Adorno's theory of musical reproduction differs greatly from the ideas about reproduction that I have discussed 
up to this point. For Adorno, reproduction and interpretation go hand-in-hand; there is a distinct difference between the original and the reproduction. This view of reproduction relies on the fact that musical notation is a representation of an idea, not the idea itself. In a way, Adorno views musical reproduction through a semiotic lens. Musical notation is far too imperfect to encapsulate every variable in a composer's song, but if the composer does not perform the song, it can only be a representation. For example, there is no way to represent timbre on a score. Or, mf (which means medium volume) may be a radically different volume in the 15th century England than 21st century America. Or, allegro, a tempo marking that means lively or rather quick, may change in meaning after punk music because what it means to be "rather quick" has changed. Over time, the meaning of what is written changes correspondingly. There are also two ways that performers can interpret music: 1) interpreting in the present or 2) interpreting in an imagined past. In either case, Adorno suggests that all that remains is an interpretation. Adorno asserts that the interpretation of musical notation is musical reproduction, and without interpretation, reproduction ceases to exist.

In fact, Adorno claims that "The history of musical reproduction in the last century has destroyed reproductive freedom" (Adorno 2002a:413). He identifies a shift from the interpretive nature of reproduction to the literal or mechanical reproduction of music. Whereas the individual performing a reproduction had artistic freedom when reading a score, the individual playing a recorded album lacks any ability to interpret. He says "In contrast to the nineteenth century, the decisive change experienced by contemporary musical reproduction is the destruction of the balance of individualistic society and individualistic production; the freedom of reproduction has therewith grown highly problematic, and nowhere is this seen more clearly than in the transition from competitive to monopoly capitalism" (Adorno 2002a:413). This shift is the product of a shift in capitalism. Mechanical reproduction is the consequence of a monopoly capitalism that attempts to enclose all commodities in order to extract the most profit as possible out of a single moment of production (i.e. a recording).

Whereas Walter Benjamin sees the democratic potential in mechanical reproduction by giving the masses access to art (Benjamin 1936), Adorno sees this mass reproduction as enabling a particular form of monopoly capitalism. Adorno claims that while recordings may expose a mediocre performer to some of the greatest performances, it also creates the room for that mediocre performer to create a second-hand interpretation that is in the end merely an imitation (Adorno 2006:24). In other words, bad performers can record bad music and sell it to the masses; I would add that some people are able to do this by virtue of having access to capital. For instance, Taylor Swift's father purchased part of a record label to get Swift her start. Mechanical reproduction, in Adorno's terms, is not about access to the means of consumption, it is about access to the means of production.

\section{Jacques Attali}

This issue of access to the means of consumption versus access to the means of production comes across in another theorization of mechanical reproduction. In Noise (Attali 1985), French economist Jacques Attali lays out the political economy of four modes of production for music. First, Sacrificing is a primitive economy that relies on the sacredness of music as a cultural form and depends on patronage by the aristocracy. Second, Representing is a mode of production brought about by the bourgeoisie in their attempt to demonstrate their newfound economic strength. Representing involves public performances by musicians reading musical notation. Third, Repeating is a mode of production brought about by industrial capitalism. Repeating uses mechanical reproduction to distribute recordings to the masses. Fourth, Composing is a future mode of production that Attali thinks will involve individuals writing music on computers for their own enjoyment - while Attali published this book in 1988, this fourth category is quite attuned to what seems to be happening with Digital Audio Workshops (such as Garage Band or Pro-Tools) today. What interests me here is the relationship between Attali's Representing and Repeating modes of musical production and a concept of musical reproduction.

During representing, the bourgeoisie were increasingly trying to assert their new economic and political power through cultural means. Their numbers required them to replace the court "jester" with orchestras. Going to concerts represented the bourgeoisie's newfound power. At the same time, in Adorno's terms, the performers were playing representations of compositions. Copyright was also developed at this time as a means to pay composers for their compositions - under this social relation of production the performers were required to pay the composers out of their income from performances. "In the beginning," Attali argues, "the purpose of copyright was not to defend artists' rights, but rather to serve as a tool of capitalism in its fight against feudalism” (Attali 1985:52). Copyright 
aided in the transition to capitalism by enabling the enclosure of ideas. In this way, money began to circulate as a result of musical performances. Each performance was a reproduction of a written composition. This is where the idea of musical piracy arises - an unauthorized performance (i.e. reproduction) was considered a pirate performance. Furthermore, it was a violation of copyright law not to pay the composer for the performance. This type of pirated performance seems entirely removed from our conceptions of piracy today.

During repeating, everyone can experience music with little to no economic power. Mechanical reproduction created the condition which would allow music to reach the masses. Whether this was through radio or records, everyone could hear the same music. Attali claims that "A new society emerged, that of mass production, repetition, ... Usage was no longer the enjoyment of present labors, but the consumption of replications" (Attali 1985:8788). Repeating is a mode where performance and consumption are disassociated; it enables time shifting. Unlike Benjamin, Attali views mechanical reproduction with suspicion because of the effects that it has on labor. Mechanical reproduction undercuts labor by allowing a handful of musicians to make the vast majority of reproductions. This process was visible in mid-century America as musicians in the American Federation of Musicians, the musicians' labor union, resisted soundtracks in Hollywood films because it eliminated positions for musicians in pit orchestras at movie theaters across the country (Zinn, Kelley, and Frank 2002).

But for Attali, time shifting goes beyond the disassociation between performance and consumption to the time embedded in the recording. He contends that recording

makes the stockpiling of time possible ... For we must not forget that music remains a very unique commodity; to take on meaning, it requires an incompressible lapse of time, that of its own duration. Thus the gramophone, conceived as a recorder to stockpile time, became instead its principal user ... The major contradiction of repetition is in evidence here: people must devote their time to producing the means to buy recordings of other people's time (Attali 1985:101).

People must work to make money, which they use to buy recordings. In this way, repetition enables capitalism. Adorno and Marx would explain this in terms of reproduction of the worker: i.e. workers labor more to purchase commodities to consume in their "leisure" time. Or in Adorno's words, "Amusement under late capitalism is the prolongation of work" (Horkheimer and Adorno 1972:137).

\section{Conclusion and Implications}

One conclusion that can be drawn from this analysis is that any discussion of musical reproduction is alwaysalready a discussion anchored in capitalism. Yes, the term "piracy" only categorizes that which is explicitly commercial, so any reproduction that does not include an economic exchange cannot be piracy. However, this characterization may be splitting hairs. Since musical reproduction is a product of capitalism, it is always only a matter of time before corporations use their power to reconfigure the law to facilitate the commodification of music. For that reason, I think it is important to attempt to develop a new conceptual framework for music that can exist without using reproduction.

Some may argue that the Internet provides alternatives to this system by allowing musicians to interact directly with their fans. This could give musicians control that allows them to determine how their fans will listen to music. They can distribute their music online for free; use music as an advertisement to get people to shows, etc. However, this is a short slippery slope to other ways of monetizing music or just a step that circumvents major record labels. Agger calls this enthusiasm technological utopianism - a term that he uses to describe those who felt that "virtual capitalism represents a new stage of civilization in which all social problems disappear" (Agger 2004b:6). In fact, those who push technological utopianism often develop the very ideology through which to perpetuate virtual capitalism. And this is my underlying concern about reproduction because it seems to me that as long as we discuss recordings, people (whether they are fans or musicians) begin talking about ways to make money from the sale of recordings.

Now, I am not naive enough to think that musicians could spend their life performing music without monetary compensation. As long as the mode of production is capitalism, if someone wants to perform music as a full-time job, they have to have a way to earn a wage from it. For better or worse, musical reproduction created a system where musicians were brought into capitalism through wage labor. Yet, it is only in rare instances, today, that musicians earn an adequate amount of money to earn a living from performance. Rather, musicians tend to "keep their day job" by 
working in a different industry, often precariously employed, in hopes of one day materializing their dream of playing music full-time. This is the furthest thing removed from any idealized artist earning money from the fruits of their artistic labor. The system traps musicians in a vicious cycle of underemployment, and if they are lucky enough to be on a label, debt peonage.

Some have developed alternative theorizations about ways that musicians could earn a living. For instance, economist Dean Baker proposes to eliminate copyright through an intricate public system where taxpayers could assign their taxes to performers. He proposes "a modest refundable tax credit -- an artistic freedom voucher (AFV) -- that would allow them to give \$75-\$100 a year to support creative work. This money could either go directly to the worker or to an intermediary that supports specific types of creative work" (Baker n.d.). Music fans could allocate part of their taxes to musicians who participate in the system; if not, that money would go into a general fund to be distributed equally to all participating musicians. While still relying on reproduction and wages, a system such as this would provide an opportunity outside of copyright for musicians to make money. This is not the solution, but it is an interesting place to begin thinking through the problem.

Adorno would not have been so concerned with issues of downloading music legally or illegally on the Internet. But rather, he would have been highly critical of the system that enables copyright and digital musical reproduction as we know it. Recordings themselves do not allow room for interpretation. For that reason, Adorno may have argued that people can consume music however they want because the problem lies in music's production.

I should have seen Agger's email as an invitation to place Adorno and Benjamin squarely in conversation with each other. Much of the discussion following my presentation was about the tension between these two Frankfurt School theorists. But what most surprised me was Agger's response to his own simple question, "Adorno or Benjamin?" My response was a long-winded argument for Adorno's perspective on negative dialectics and his overall contention that recording technology destroys music. Having read Agger, I expected his own response to favor Adorno. But he ended the question and answer session with the one word response "Benjamin." He never contextualized this to me, and I wish I would have pushed him on it, but now I can only assume it related to the hope to see humanity overcome the entrapments of capitalism.

\section{References}

Adorno, Theodor W. 2002a. "On The Social Situation of Music." P. p.391-433 in Essays on Music / Theodor W. Adorno, edited by T. W. Adorno, R. D. Leppert, and S. H. Gillespie. Berkeley, Calif.: University of California Press.

Adorno, Theodor W. 2002b. "The Form of the Phonograph Record." Pp. 277-80 in Essays on Music / Theodor W. Adorno, edited by T. W. Adorno, R. D. Leppert, and S. H. Gillespie. Berkeley, Calif.: University of California Press.

Adorno, Theodor W. 2006. Towards a Theory of Musical Reproduction: Notes, a Draft and Two Schemata . 1st ed. edited by H. Lonitz. Malden, MA: Polity.

Agger, Ben. 2004a. Speeding Up Fast Capitalism: Cultures, Jobs, Families, Schools, Bodies. Boulder, Colo: Routledge.

Agger, Ben. 2004b. The Virtual Self: A Contemporary Sociology . Malden, Mass: Blackwell.

Arditi, David. 2014a. "Downloading Is Killing Music: The Recording Industry's Piracy Panic Narrative” edited by V. Sarafian and R. Findley. Civilisations 63(1):13-32.
Arditi, David. 2014b. iTake-Over: The Recording Industry in the Digital Era . Lanham, Maryland: Rowman \& Littlefield Publishers.

Attali, Jacques. 1985. Noise: The Political Economy of Music. Minneapolis: University of Minnesota Press.

Baker, Dean. n.d. "The Surefire Way to End Online Piracy: End Copyright." Truthout. Retrieved March 13, 2013 (http:// www.truth-out.org/opinion/item/6230:the-surefire-way-toend-online-piracy-end-copyright).

Benjamin, Walter. 1936. "The Work of Art in the Age of Mechanical Reproduction.” Retrieved (http://www.marxists. org/reference/subject/philosophy/works/ge/benjamin.htm).

Frith, Simon. 2006. “The Industrialization of Music.” P. xxii, 408 p. in The Popular Music Studies Reader, edited by A. Bennett, B. Shank, and J. Toynbee. London; New York: Routledge.

Horkheimer, Max and Theodor W. Adorno. 1972. "The Culture Industry: Enlightenment as Mass Deception.” P. xvii, 258 p. in Dialectic of Enlightenment. [New York]: Herder and Herder. 
Krasilovsky, M.William, Sidney Shemel, John M. Gross, and Jonathan Feinstein. 2007. This Business of Music. 10th ed. Billboard Books.

Patry, William. 2009. Moral Panics and the Copyright Wars . 1st ed. Oxford University Press, USA.

Shuker, Roy. 2012. Popular Music Culture: The Key Concepts. 3rd ed. Routledge.

Sterne, Jonathan. 2003. The Audible Past: Cultural Origins of Sound Reproduction . 1st edition. Durham: Duke University Press Books.
Théberge, Paul. 2006. "Music/Technology/Practice: Musical Knowledge in Action.” P. p.283-291 in The Popular Music Studies Reader, edited by A. Bennett, B. Shank, and J. Toynbee. London; New York: Routledge.

Zinn, Howard, Robin D. G. Kelley, and Dana Frank. 2002. Three Strikes: Miners, Musicians, Salesgirls, and the Fighting Spirit of Labor's Last Century. Boston: Beacon Press. 
